AperTO - Archivio Istituzionale Open Access dell'Università di Torino

\title{
Evaluation of seed dressing dust dispersion from maize sowing machines
}

\section{This is the author's manuscript}

Original Citation:

Availability:

This version is available http://hdl.handle.net/2318/1616702

since 2016-11-25T15:03:51Z

Published version:

DOI:10.1016/j.cropro.2013.04.012

Terms of use:

Open Access

Anyone can freely access the full text of works made available as "Open Access". Works made available under a Creative Commons license can be used according to the terms and conditions of said license. Use of all other works requires consent of the right holder (author or publisher) if not exempted from copyright protection by the applicable law. 


\section{Evaluation of seed dressing dust dispersion from maize sowing}

\section{3 machines}

4

PAOLO BALSARI, MARCO MANZONE, PAOLO MARUCCO and MARIO TAMAGNONE

University of Turin, DEIAFA - Mechanics Section, Via L. Da Vinci, 44, 10095 Grugliasco, Italy

7

8

Abstract

9 The present study analysed the constructive and operative parameters of pneumatic

10 seeders and researched and assessed possible technical solutions for limiting the

11 unwanted dispersion of dust from seed dressing during sowing of maize seeds. Tests

12 were made on several maize pneumatic seeder models. The air flow rates and the air

13 velocities at the fan outlet were assessed, the sizes of the areas contaminated with the

14 material from the maize seeds was evaluated and the air velocities along the contour of

15 the sowing machines were measured. Results showed that by decreasing the fan air flow

16 rate by $30 \%$ it was possible to consistently reduce the size of the area contaminated by

17 seed dressing dust while maintaining a good quality of seeding. They also showed that

18 the technical solutions proposed by the seeder manufacturers reduced the environmental

19 contamination with the pesticide-containing dust by more than $90 \%$.

20

21 Key words: Sowing machine, maize seed, neonicotinoids, bee. 
1

\section{Introduction}

2

3 In the last few years several honey bee poisoning incidents have been reported that were related 4

to sowing maize seeds treated with neonicotinoid insecticides using pneumatic seeders

\section{(Altmann, 2003; Greatti et al., 2003; Schnier et al., 2003; Greatti et al., 2006; Baldessari et al.,} 2008, Girolami et al, 2009). The air stream generated by the fan of the seeders in order to create

the necessary depression in the sowing element of the machine, in fact, is considered responsible

for blowing the solid dust particles detached from the seeds towards the areas adjacent to the seeded field. Actually, the use of maize seed dressed with neonicotinoids is currently banned in Italy, while it is allowed, with some limitations, in other European countries (Table 1).

This paper reports experimental tests to study the constructive and operative parameters of maize pneumatic seeders and to assess technical solutions enabling to limit the seed dressing material dispersion from these machines.

\section{Materials and Methods}

Preliminary tests were conducted in order to assess the main seeder parameters influencing the dispersion of dust material. In detail, for each sowing machine tested, the following measurements were made: 1) fan air flow rate, 2) depression in the seeding elements and 3) air velocity along the contour of the seeders. These parameters were determined either according to the machine setup suggested by the seeder manufacturer or in operative conditions enabling guaranteeing a high quality seeding with a reduced environmental impact.

Tests were made using three pneumatic seeders $(\mathrm{A}-\mathrm{B}-\mathrm{C})$, representative of the Italian context (Table 2). Each machine was tested either in its standard configuration or in modified configurations with the purpose of limiting dust dispersion. The seeding was done at a distance 
1 of $0.75 \mathrm{~m}$ between the maize rows and at a (seeding) rate of 75,000 seeds per hectare. Seeder A

2 was tested in its standard configuration and in a modified one where the air was conveyed

3 between the wheels of each seeding element. In particular, in the standard configuration, the

4 seeder had an "air deflector" on the fan outlet to deflect the air towards the soil.

5 Seeder B was tested, in addition to in its standard configuration, in two further configurations

6 aimed at reducing dust dispersion: one had four $100 \mathrm{~mm}$ diameter air hoses conveying the air

7 towards the soil, the second had one $55 \mathrm{~mm}$ diameter air hose for each seeding element,

8 conveying the air close to the share of the seeding furrow. Seeder C was tested in its standard

9 configuration and in a modified one where the fan air outlet was conveyed toward the soil by

10 two hoses of $125 \mathrm{~mm}$ diameter.

\subsection{Fan air flow rate}

14 The fan air flow rate was measured both at the fan outlet and at the fan inlet using a $110 \mathrm{~mm}$

15 diameter conveyor $1 \mathrm{~m}$ long where a propeller anemometer (Allemano Testo 400) with $0.1 \mathrm{~m} \mathrm{~s}^{-1}$ accuracy was positioned. Tests were made with and without seeds present in the hopper.

Measurements were carried out at the PTO revolutionary speeds recommended by the

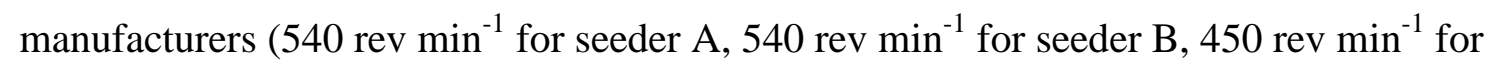

19 seeder C).

\subsection{Depression in the seeding element}

The depression in the seeding element was measured through a water manometer placed in the connection hose between the seeding element and the fan. The water manometer was made from two vertical tubes of $16 \mathrm{~mm}$ internal diameter and $2 \mathrm{~m}$ height. The difference in the height of the two different water levels was determined using a ruler with $1 \mathrm{~mm}$ accuracy. 
1 Measurements were carried out at five different PTO revolutionary speeds $(300,350,400,450$,

2500 and $540 \mathrm{rev} \mathrm{min}^{-1}$ ) and using only the pneumatic seeder B with one to six seeding elements.

\subsection{Air velocity along the contour}

5

6 The measurements were done with the seeders in a static position and placed indoors, using the

7 propeller anemometer (Allemano Testo 400) described above mounted on a rigid support and

8 making measurements at different heights from the ground. For machines A and B the air

9 velocity was measured at heights of $0.05,0.50$ and $1.00 \mathrm{~m}$ in steps of $0.30 \mathrm{~m}$ along the machine contour. For seeder C, which had an upwards - directed air outlet (therefore with a different air

11 flow rate profile), the air velocity measurements were made out following a grid of measurement 12 points at distances ranging from 0 to $3 \mathrm{~m}$ from the machine and at heights from 0 to $3 \mathrm{~m}$ from 13 the ground. Intervals between measuring points within the grid were $0.25 \mathrm{~m}$ (Fig. 1).

14 In all tests, for each measuring point, the anemometer was oriented to detect the maximum air velocity with respect to the air stream. Tests were conducted employing the sowing machines with and without seeds in the hoppers, using the fan rotational speed recommended by the manufacturer and using 4 or 6 seeding elements. Each trial was carried out with environmental conditions of $20-25^{\circ} \mathrm{C}$ air temperature and $65-70 \%$ relative humidity.

\subsection{Footprint of the dust material}

22 In order to measure the footprint of the dust material dispersed from the seeders, tests were carried out in the laboratory simulating the seeding operation with the machine in a static

24 position and using an experimental powder instead of the insecticide seed dressing material. The powder used in the tests was selected after analysing the particle sizes of the dust material expelled from the air outlets of the seeders when using dressed maize seeds $\left(\mathrm{KWS}^{\circledR}\right.$ and 
1 Pioneer $^{\circledR}$ ). To collect this dust material a "cyclone vacuum cleaner" (characterized by vacuum air

2 flow rate of $260 \mathrm{~m}^{3} \mathrm{~h}^{-1}$ and $97 \%$ efficiency separation) was used and the particles size analysis

3 was made through an image analysis system (Image Pro Plus ${ }^{\circledR}$ ).

5 In order to select the inert material for simulating the dress maize powder, tests were made using

6 wheat flour " 00 " (a cheap and widely available material) and considering the Volumetric Median

7 Diameter (VMD) value.

8 For each material (maize seed dressing and wheat flour " 00 "), the diameters of the granules were

9 determined using the specific software Image Pro Plus ${ }^{\circledR}$ on five samples of at least 2000 particles

10 obtained from 50 images acquired by a Epix Sv 5 C10 5 Mpixel camera with a $1.4 \mu \mathrm{m}$ pixel $^{-1}$

11 resolution equipped with a Nikon ${ }^{\circledR}$ AF Micro Nikkor $60 \mathrm{~mm}$ lens.

13 Statistical analysis (ANOVA) showed that the wheat flour " 00 " had physical characteristics very

14 similar to the maize seed dressing material and therefore it was used to assess the dust dispersion

15 from the sowing machines (Table 3).

16 Wheat flour powder was then manually introduced in the fan inlet, through a branch of the pipe

17 that connected the fan to the seeding element, at a rate of $35 \mathrm{~g}$ in 10 minutes. The amount of

18 powder introduced in the fan inlet was weighed using a balance (Kern, abs 220-4) with $0.1 \mathrm{mg}$

19 accuracy. The material dispersed on the ground around the machine, collected on Petri dishes

20 (138 mm diameter) positioned at intervals of $100 \mathrm{~mm}$ under and around the seeders up to a

21 distance of 4 meters from the machine, was determined by weight. Based on the deposits

22 detected on the Petri dishes, the area of the dust footprint was calculated and expressed in $\mathrm{m}^{2}$. A

23 powder rate of $35 \mathrm{~g}$ per 10 min was used because this was the minimum quantity that enabled

24 detection of deposits on Petri dishes using a balance (Kern, abs 220-4) with $0.1 \mathrm{mg}$ accuracy. 
1 All tests were made using A, B and C sowing machines either in their standard configuration or

2 mounting the devices to convey the air towards the soil and keeping a depression of 42 mbar in

3 the seeding elements, a value that according to G. Bragatto (pers. comm.) is considered optimal

4 for correct maize seeding. For each test, five replicates were made and dust footprint areas were

5 statistically analysed with Ryan-Einot-Gabriel-Welsch test with an $\alpha$ coefficient of 0.05 .

6

7 3. Results and discussion

\subsection{Fan air flow rate}

For each seeder tested, the air flow rate did not differ when measured at the fan inlet or at the fan outlet (Table 4).

13 Tests made without the maize seeds in the seeding hopper showed higher air flow rates for the $\mathrm{C}$

14 and the B machines (75 and $80 \mathrm{~m}^{3} \mathrm{~h}^{-1}$ per seeding element, respectively). The presence of the 15 seeds in the hopper decreased the outlet air flow rate by about 55\% (Fig. 2).

\subsection{Depression in the seeding element}

The depression value, measured in the seeding element, recorded at the PTO revolutionary speeds recommended by the manufacturers (ranging from 450 to $540 \mathrm{rev} \mathrm{min}^{-1}$ depending on seeder model), was between 60 and 67 mbar, about $30 \%$ more than the optimal value (42 mbar) suggested for a good quality of maize seeding (Bragatto, pers. comm.) (Fig. 3). Optimal depression values were generally obtained when the PTO revolutionary speed was set between

24350 and $400 \mathrm{rev} \min ^{-1}$. The depression value in the seeding element that resulted was influenced by the fan rotational speed but was independent of the number of seeding elements mounted on the machine (Fig. 4). 
4 Air velocity measured along the contour of the machine differed according to the position and

5 the shape of the fan outlet. Tests carried out on sowing machine A in the standard configuration

6 and equipped with six seeding elements showed that the air stream generated by the fan was

7 biased towards the soil on the right side of the machine (Fig. 5). The air velocities measured at

8 the right edge of the machine were about $1.0 \mathrm{~m} \mathrm{~s}^{-1}$ up to $0.05 \mathrm{~m}$ height from the ground. At

9 heights over $0.05 \mathrm{~m}$ from the ground, the air velocities recorded did not exceed $0.5 \mathrm{~m} \mathrm{~s}^{-1}$ (Fig. 5).

10 B sowing machine, that had its fan outlet oriented downwards, generated an air stream oriented

11 towards the soil on the left side of the machine, with a velocity, measured in correspondence of

12 the left edge of the machine, of $2.2 \mathrm{~m} \mathrm{~s}^{-1}$ when the seeder was equipped with four seeding

13 elements and of $1.3 \mathrm{~m} \mathrm{~s}^{-1}$ when it was equipped with six elements. It was observed that, even if

14 the air outlet was oriented towards the right side of the machine, the highest air velocities were,

15 however, measured on the opposite side due to the reflection effect caused by the machine frame 16 (Fig. 6).

18 Seeder C, which had six seeding elements and had the fan outlet oriented upwards, produced an

19 air stream oriented towards the right side of the machine. In this case, air velocities higher than

$20 \quad 0.5 \mathrm{~m} \mathrm{~s}^{-1}$ were recorded even at a distance of $3 \mathrm{~m}$ from the machine edge (Fig. 7).

21 Independent of the sowing machine model, when the devices provided by the different

22 manufacturers to convey the air close to the soil were mounted, the resultant air stream always

23 kept within the machine contour. The solution proposed by the manufacturer of seeder A, which

24 conveyed the air in the chamber between the wheels of each seeding element, contained the air 25 stream within the chamber itself (Fig. 5, 6 and 7) 
2

3 Tests carried out using the B sowing machine showed that the dust blown out by the fan

4 deposited on a surface of about $6 \mathrm{~m}^{2}$ and that most of it (90\%) was within the machine footprint

5 when equipped with six seeding elements (Fig. 8). When the A and C seeders were employed,

6 the dust footprint that resulted was larger and most of the material was collected on the left side

7 of the machine (Fig. 9 and 10). By adopting the devices to convey the air towards the soil, the

8 area of the dust footprint was considerably reduced (by more than 90\%) with respect to the

9 standard configuration and it was always within the machine footprint (Table 5).

11 In conclusion, the use of devices conveying the air generated by the fan of pneumatic seeders

12 towards the soil reduced the air stream profile by $80 \%$ and therefore the size of the ground area 13 contaminated with dust.

14 Moreover, test results showed that, for all types and configurations of seeders it is also possible

15 to reduce the environmental contamination due to maize seed dressings just by lowering the fan revolutionary speeds on pneumatic seeders. For example, experiments revealed that decreasing

17 by about $1000 \mathrm{rev} \mathrm{min}^{-1}$ this parameter (that corresponds to a decrease of about $100 \mathrm{rev} \mathrm{min}^{-1}$ of 18 the PTO), resulting air flow rate and air velocity generated by the fan were reduced by about $1930 \%$ and this significantly limited the surface contaminated by the seed dressing material,

20 guaranteeing at the same time the necessary depression in the seeding elements.

21 In order to assess other constructive and operative parameters and other solutions proposed by

22 maize seeders manufacturers, further tests will be carried out at DEIAFA. 
1

2

\section{References}

Altmann R., 2003. Poncho: a new insecticidal seed treatment for the control of the major maize pests in Europe. Pflanzenschutz-Nachrichten Bayer (English edition) 56, 102-110

Baldessari M., Trona F., Leonardelli E., Angeli G., 2008. Efficacia di acetamiprid e di azadiractina nel contenimento di Dysaphys plantaginea. Procedine of national conference "Giornate Fitopatologiche 2008"

Girolami V., MazzonL., Squartini A., Mori N., Marzaro M., Di Bernardo A., Greatti M., Giorio C., Tapparo A., 2009. Translocation of neonicotinoid Insecticides From Coated Seeds to Seedling Guttation Drop: A Novel Way Intoxication for Bees. Journal Econ. Entomol. 102, $1808-1815$

Greatti M., Sabatini A.G., Barbatini R., Rossi S., Stravisi A., 2003. Risk of environmental contamination by the active ingredient imidacloprid used for corn seed dressing. Preliminary results. Bulletin of Insectology 56, 69-72

Greatti M., Barbatini R., Stravisi A., Sabatini A.G., Rossi S., 2006. Presence of the a.i. imidacloprid on vegetation near corn fields sown with Gaucho dressed seeds. Bulletin of Insectology 59, 99-103.

Pioneer, 2010. Catalogo prodotti 2010.

Schnier H. F., Wenig G., Laubert F., Volker S., Schmuck R., 2003. Hey bee safety of imidacloprid corn seed treatment. Bulletin of insectology 56, 73-75

\section{Acknowledgement}

This research was funded by Agrofarma (Italian Association of the pesticides industry) 
2 Fig. 1 - Measuring points of the air velocity around the $\mathrm{C}$ seeders

3 Fig. 2 - Fan outlet air flow rate measured on the seeders with and without the maize seeds in the hopper of the seeding element.

$5 \quad$ Fig. 3 - Depression inside the seeding element measured in the tested seeders

6 Fig. 4. - Depression measured inside the seeding element as a function of the number of seeding elements present on the machine and of the PTO revolution speed.

8 Fig. 5 - Characteristics of the air stream generated by the fan of A seeders (front view of the 9 machine)

10 Fig. 6 - Characteristics of the air stream generated by the fan of B seeders (front view of the 11 machine)

12 Fig. 7 - Characteristics of the air stream generated by the fan of $\mathrm{C}$ seeders (front view of the 13 machine)

14 Fig. 8 - Dust deposits on the ground measured using the B sowing machine.

15 Fig. 9 - Dust deposits on the ground measured using the A sowing machine.

16 Fig. 10 - Dust deposits on the ground measured using the $\mathrm{C}$ sowing machine 17 


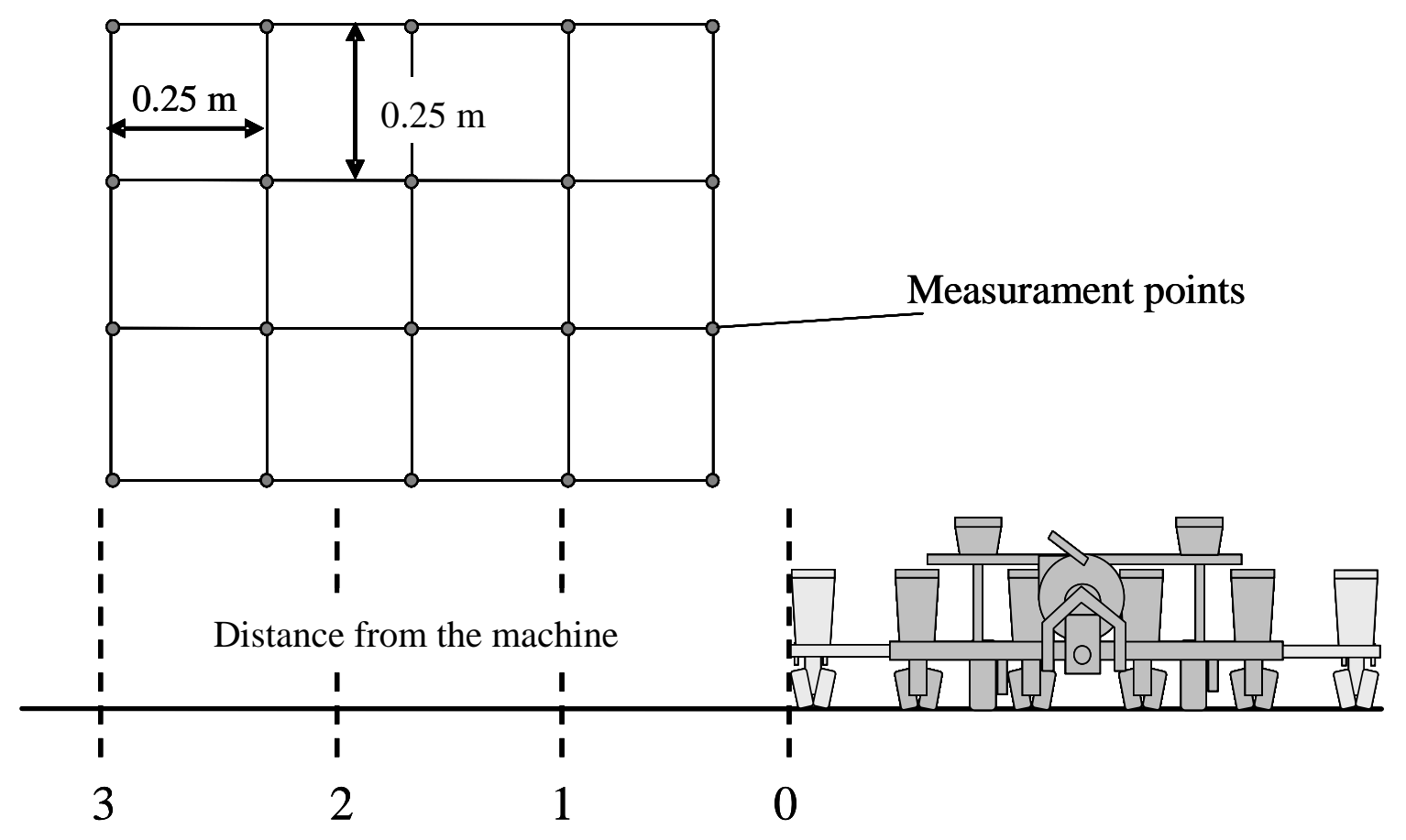

$3 \quad$ Figure 1

4 


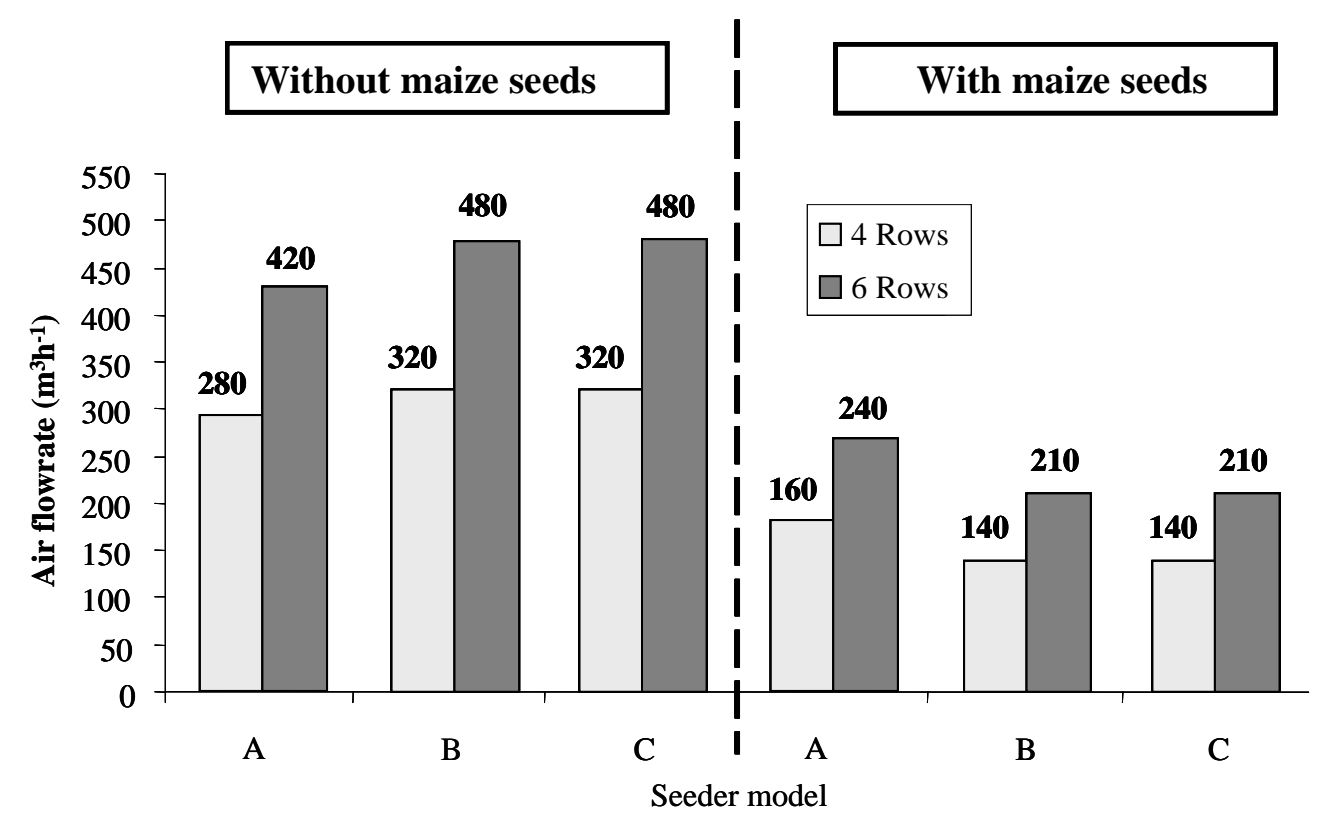

2 Figure 2 


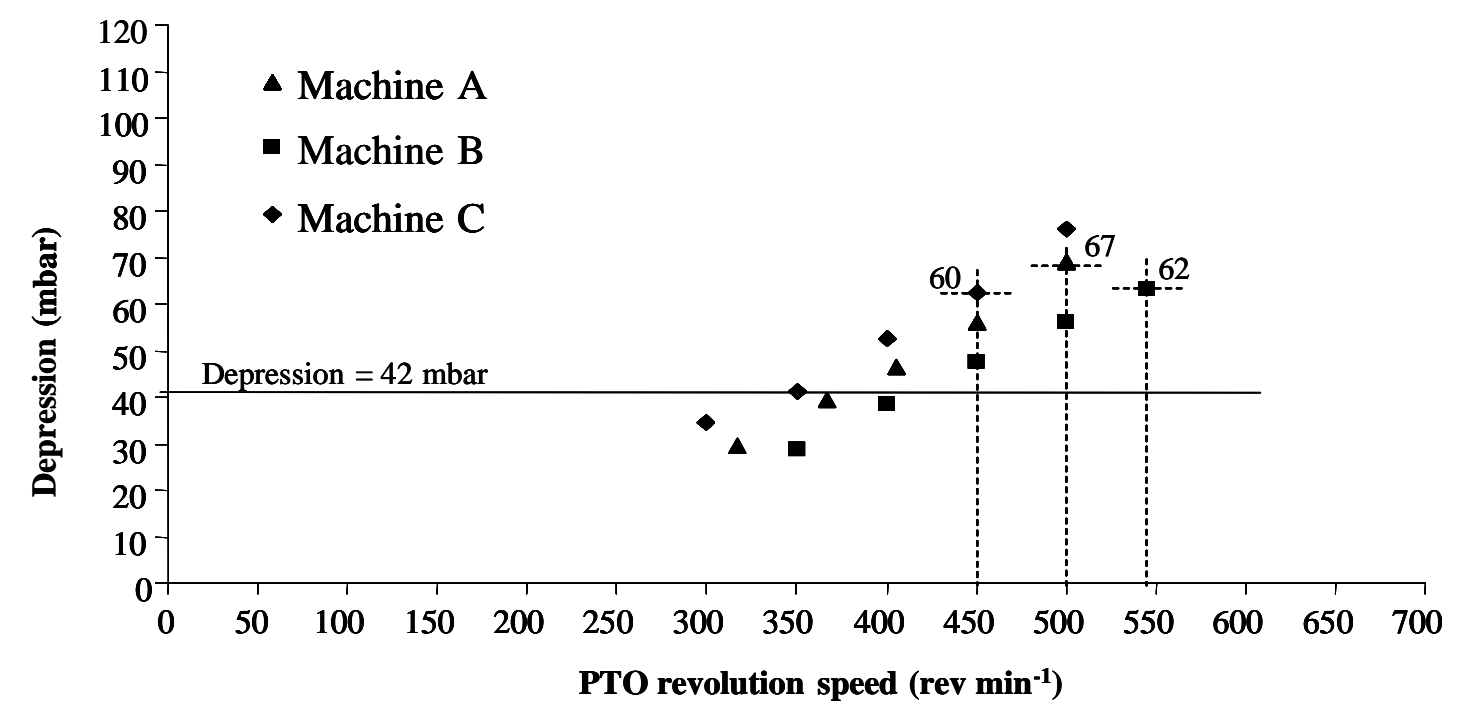

$2 \quad$ Figure 3

3 


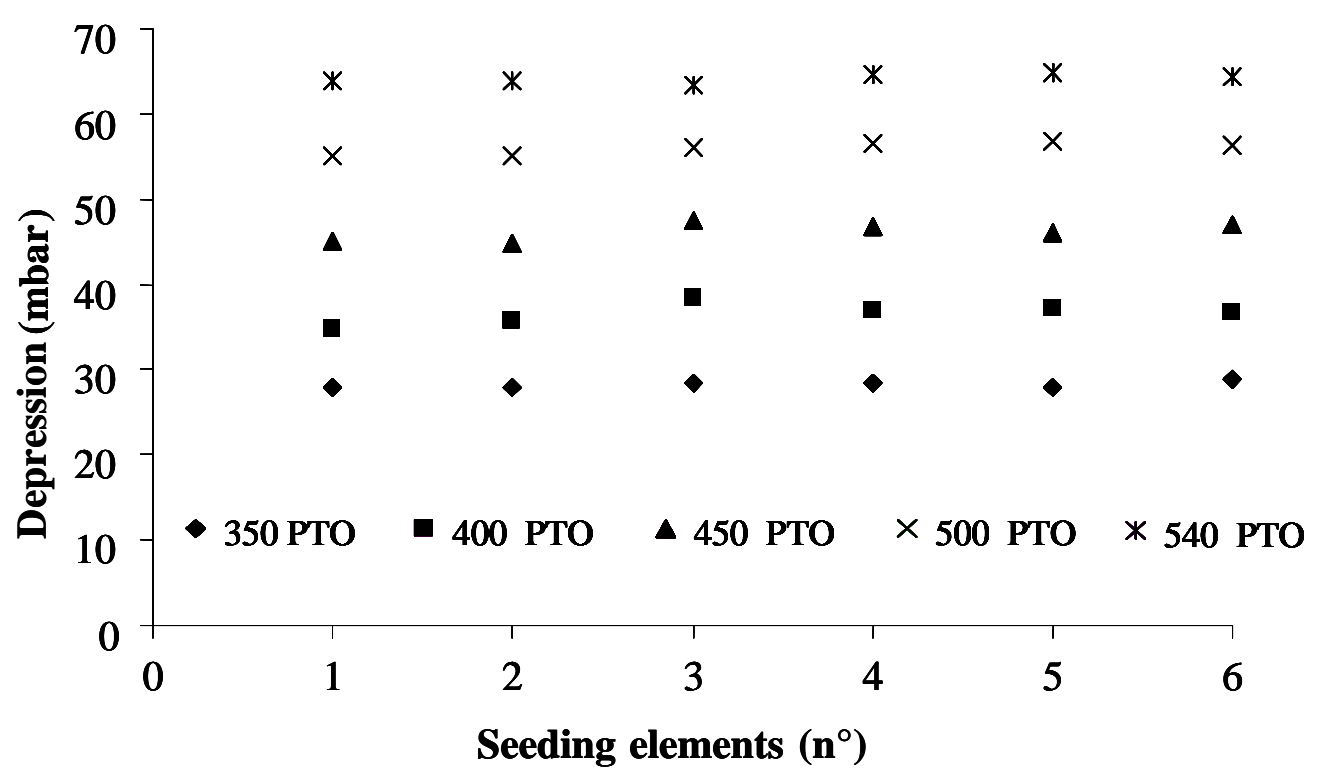

2 Figure 4

3 
Standard configuration

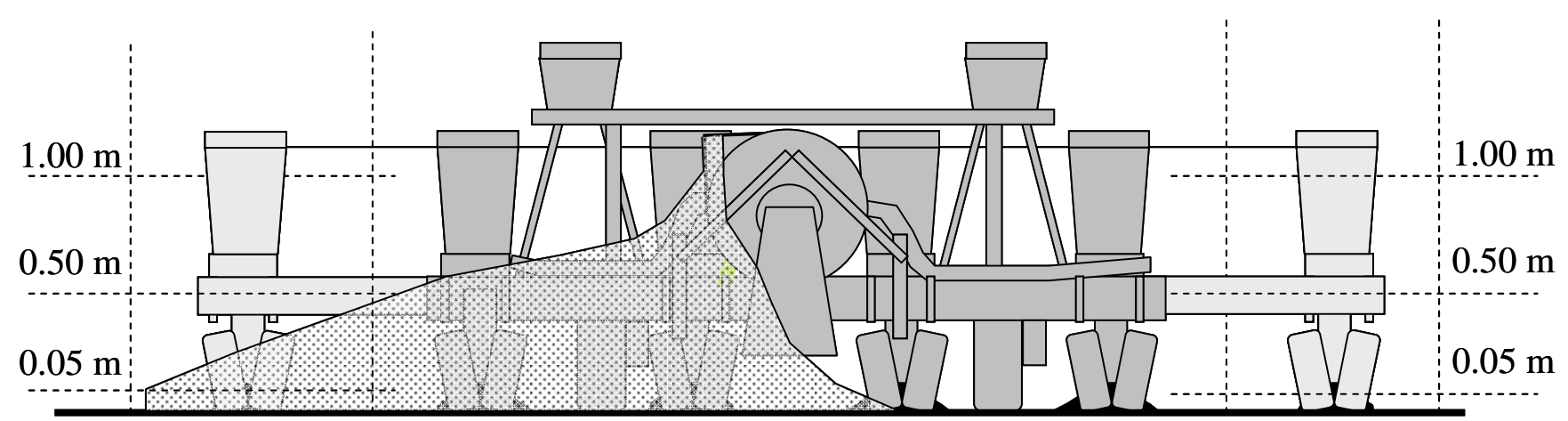

2 Figure 5 
: Standard configuration $\quad$ N Modified configuration (1) $\quad$ Modified configuration (2)

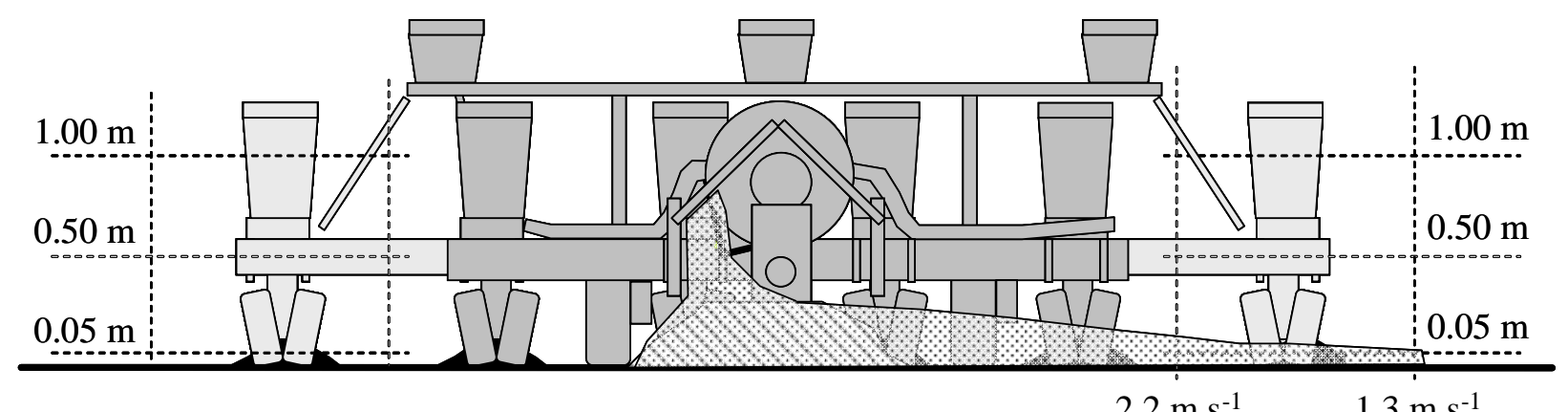

1

$2.2 \mathrm{~m} \mathrm{~s}^{-1}$

$1.3 \mathrm{~m} \mathrm{~s}^{-1}$

2 Figure 6

3 


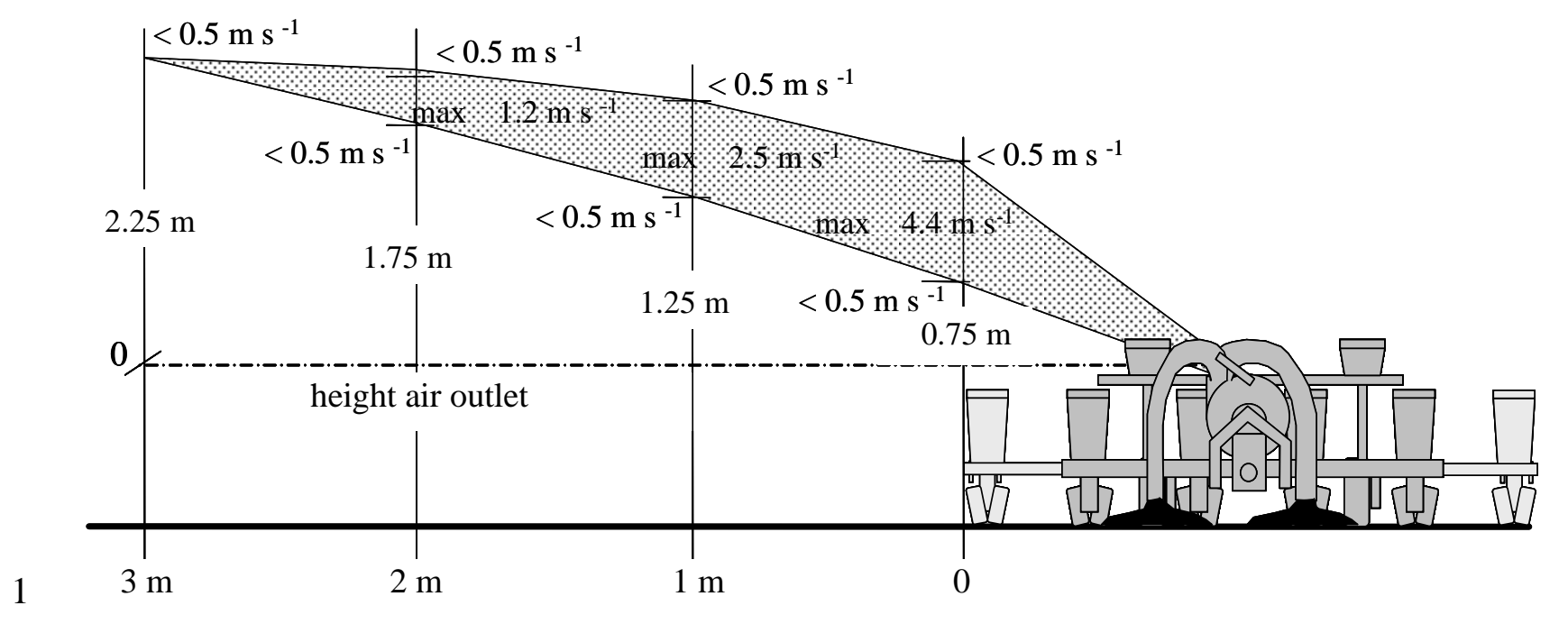

$2 \quad$ Figure 7 


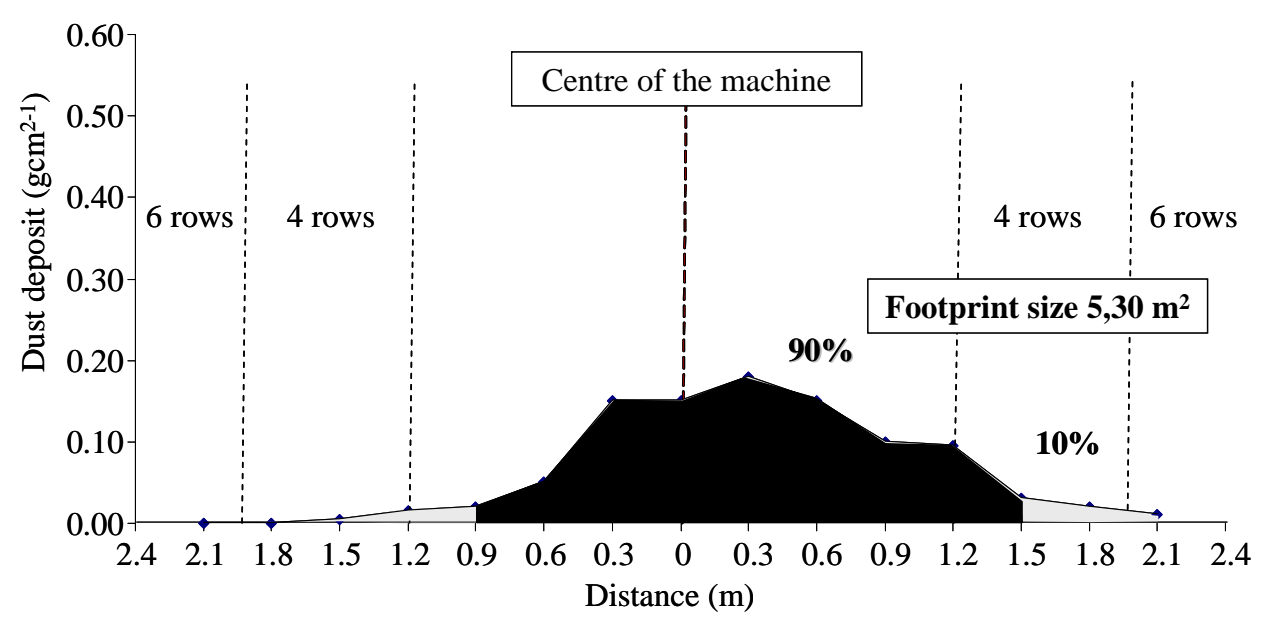

$2 \quad$ Figure 8 


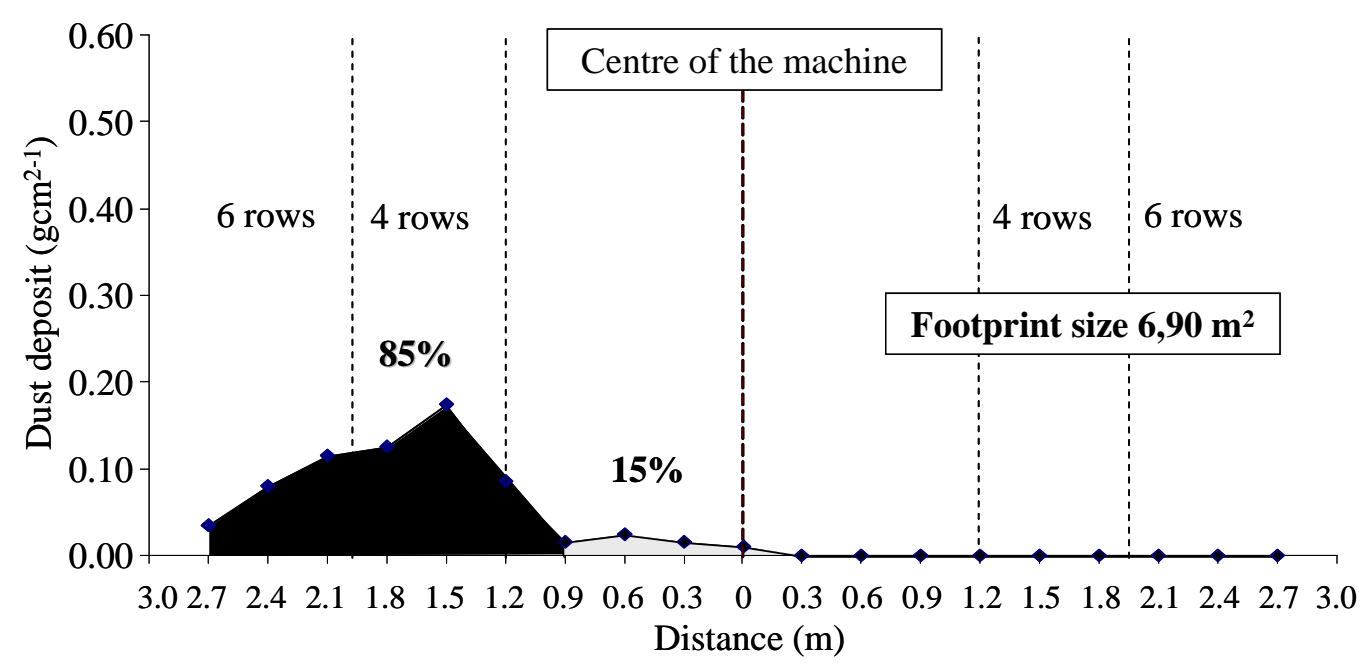

2 Figure 9

3 


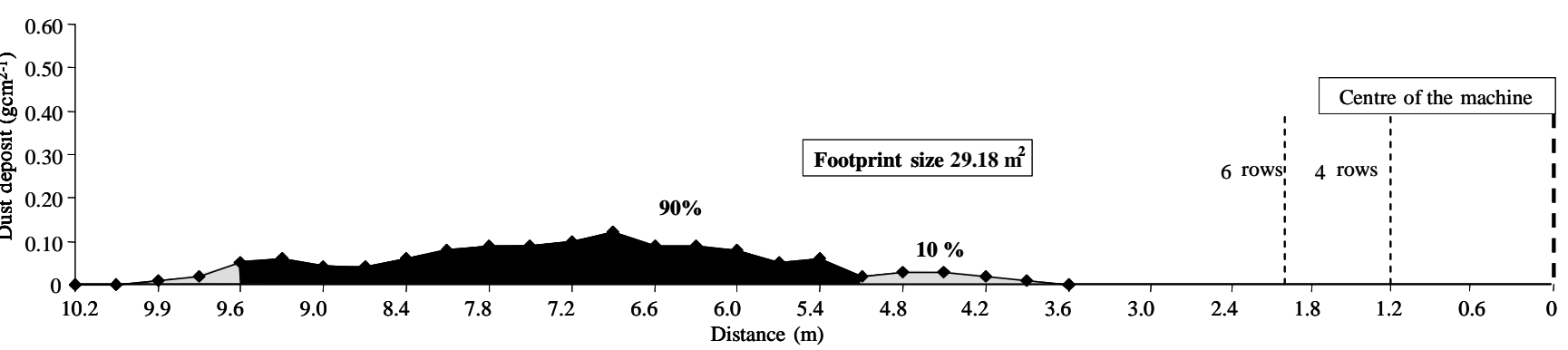

2 Figure 10 
2 Table 1 - Neonicotinoides insecticides use allowed in European countries (Pioneer ${ }^{\circledR}$,

$32010)$

4 Table 2 - Main technical features of the fans present on the pneumatic seeders tested.

5 Table 3 - Physical characteristics of the dressing seed dust and of the selected tracer (wheat flour “00”). No significant difference - Statistical analysis ANOVA unvaried, $\mathrm{p}>0.05$.

7 Table 4 - Air flow rate $\left(\mathrm{m}^{3} \mathrm{~h}^{-1}\right)$ measured at the fan inlet and at the fan outlet of the pneumatic

8 seeder B

9 Table 5 - Size of the dust contaminated surface assessed with the conventional pneumatic

10 seeders and with the modified ones, equipped with devices to convey the air towards the soil

11 (REGW, Alfa= 0.05)

12

13

14 


\begin{tabular}{lccc}
\hline & Clothiandin & Fipronil & Thiamethoxan \\
\hline Austria & yes & yes & yes \\
Belgium & no & yes & yes \\
UK & no & no & yes \\
France & no & no & yes $\left(^{*}\right)$ \\
Germany & yes $(*)$ & no & yes $(*)$ \\
Italy & no & no & no \\
Netherlands & no & no & yes \\
Slovenia & yes & no & yes \\
Spain & no & yes & yes \\
Switzerland & yes & no & yes
\end{tabular}

2 (*) Only if the seeding operation is performed with pneumatic seeders equipped with a kit for convey the air stream

3 toward the soil

$4 \quad$ Table 1

5 


\begin{tabular}{|c|c|c|c|}
\hline Manufacturer & $\mathbf{A}$ & $\mathbf{B}$ & $\mathbf{C}$ \\
\hline Model & Ma/ag-SD05 & Gaspardo-MT & Monosem -NG-plus \\
\hline Rows $\left(\mathrm{n}^{\circ}\right)$ & $4-6$ & $4-6$ & $4-6$ \\
\hline Fan diameter $(\mathrm{mm})$ & 440 & 410 & 420 \\
\hline Fan width (mm) & 45 & 60 & 80 \\
\hline Blades $\left(n^{\circ}\right)$ & 10 & 10 & 8 \\
\hline Blade inclination $\left(^{\circ}\right)$ & 30 & 31 & 0 \\
\hline Blade width (mm) & 30 & 30 & 45 \\
\hline Air outlet size (mm) & $105 \times 45$ & $230 \times 60$ & $135 \times 80$ \\
\hline Air direction & lateral & downwards & Upwards \\
\hline Fan rotation speed $\left(\right.$ rev $\left.\min ^{-1}\right)$ & 5000 & 5400 & 4500 \\
\hline
\end{tabular}

2 Table 2

3

4 


\begin{tabular}{lcc}
\hline Size particles & Dressing seed & Wheat flour \\
\hline $\mathrm{D}_{10}(\mu \mathrm{m})$ & $34,1 \mathrm{~ns}$ & $35,4 \mathrm{~ns}$ \\
$\mathrm{D}_{50}(\mu \mathrm{m})$ & $84,1 \mathrm{~ns}$ & $74,1 \mathrm{~ns}$ \\
$\mathrm{D}_{90}(\mu \mathrm{m})$ & $180,9 \mathrm{~ns}$ & $163,5 \mathrm{~ns}$ \\
Density $\left(\mathrm{g} \mathrm{cm}^{3-1}\right)$ & $0,41 \mathrm{~ns}$ & $0,45 \mathrm{~ns}$
\end{tabular}

2 Table 3

3

4 


\begin{tabular}{|c|c|c|c|c|c|c|c|c|c|c|c|c|}
\hline \multirow{3}{*}{$\begin{array}{c}\text { PTO } \\
\left(\text { rev } \text { min }^{-1}\right)\end{array}$} & \multicolumn{12}{|c|}{$\mathbf{N}^{\circ}$ seeding elements } \\
\hline & \multicolumn{2}{|c|}{1} & \multicolumn{2}{|c|}{2} & \multicolumn{2}{|c|}{3} & \multicolumn{2}{|c|}{4} & \multicolumn{2}{|r|}{5} & \multicolumn{2}{|c|}{6} \\
\hline & inlet & outlet & inlet & outlet & inlet & outlet & inlet & outlet & inlet & outlet & inlet & outlet \\
\hline 350 & 279 & 276 & 280 & 281 & 285 & 285 & 283 & 282 & 280 & 280 & 290 & 288 \\
\hline 400 & 348 & 349 & 358 & 360 & 384 & 385 & 370 & 370 & 372 & 371 & 368 & 367 \\
\hline 450 & 450 & 449 & 448 & 447 & 447 & 475 & 468 & 468 & 460 & 461 & 470 & 470 \\
\hline 500 & 550 & 550 & 550 & 548 & 560 & 561 & 566 & 565 & 568 & 569 & 562 & 563 \\
\hline 540 & 638 & 637 & 640 & 640 & 633 & 632 & 645 & 646 & 648 & 648 & 644 & 644 \\
\hline
\end{tabular}

$3 \quad$ Table 4

4

5 


\begin{tabular}{lcc}
\hline & $\begin{array}{c}\text { Surface contaminated } \\
\left(\mathbf{m}^{\mathbf{2}}\right)\end{array}$ & $\begin{array}{c}\text { Reduction } \\
(\boldsymbol{\%})\end{array}$ \\
\hline Machine A conventional & $5.27 \mathrm{c}$ & - \\
Machine A modified & $0.70 \mathrm{e}$ & 87 \\
Machine B conventional & $6.92 \mathrm{~b}$ & - \\
Machine B modified (1) & $0.54 \mathrm{e}$ & 92 \\
Machine B modified (2) & $0.63 \mathrm{e}$ & 91 \\
Machine C conventional & $29.18 \mathrm{a}$ & - \\
Machine C modified & $1.23 \mathrm{~d}$ & 96
\end{tabular}

2 Table 5

3 
3

$4>$ We studied the influence of different seeder parameters on dust dispersion.

$5>$ Reduction of seeder air flow rate decreased dust dispersion.

$6>$ Use of devices enabling the direction of the air flow towards the soil minimized dust 7 dispersion.

8 